\title{
Fé cega, faca amolada? A paráfrase como modo de representação do sujeito do discurso religioso
}

\section{Edite Luzia de Almeida Vasconcelos}

Professora do Centro Federal de Educação

Tecnológica da Bahia - CefetBA e doutoranda do

Programa de Pós-Graduação em Letras e

Lingūistica da Universidade Federal de Alagoas.

E-mail: editeluzia@ig.com.br

Resumo: Compreensão e explicação da constituição da identidade do sujeito do discurso religioso batista, por meio da análise do processo de discursividade que designa o movimento das vozes do sujeito, e também da análise do funcionamento da paráfrase e da polissemia no texto/discurso das missionárias, segundo 0 referencial da Teoria da Análise do Discurso de linha francesa.

Palavras-chave: paráfrase; polissemia; identidade; sujeito
Abstract: Understanding and explanation of the identity formation of the subject of the Baptist religious discourse, by means of an analysis of the discursive process which impose the movement of the subject voices, as well as of the analysis of the functioning of paraphrasis and polysemy in the missionaries' text/discourse, following the theoretical background of Discourse Analysis in its French orientation.

Keywords: paraphrasis; polysemy; identity; subject 



\section{Introdução}

Esta pesquisa busca compreender o funcionamento do discurso religioso e pretende demonstrar que o locutor utiliza a paráfrase e a polissemia como modos de representação do sujeito, para reproduzir a unicidade do dito divino como forma de manter a aparente homogeneidade da formação discursiva religiosa e a unidade da identidade do sujeito desse discurso.

A análise demonstrou a posição do sujeito do discurso como porta-voz do sujeito universal (Deus) na religião. Demonstrou, também, que a identidade do sujeito do discurso se constitui pelo seu modo de representação. Neste trabalho, a análise da paráfrase e da polissemia está inserida na perspectiva discursiva, tendo sido possível revelá-las tanto como marca explícita no enunciado, na esfera da intradiscursividade, quanto como trabalho do interdiscurso.

Apoiamo-nos, ainda, na noção de reversibilidade como "troca dinâmica" que ocorre durante a interlocução e como dispositivo constitutivo do discurso (ORLANDI, 1986). Para a noção de lugar, dialogamos com Maingueneau (1998), para quem o termo lugar é usado para designar a identidade dos parceiros do discurso que assumem diferentes papéis na enunciação, sendo que, nessa acepção, tal termo se refere à imagem que os interlocutores fazem de seu próprio papel instituído no discurso; e com Pêcheux (1990), para quem lugar é visto como "representado nos processos discursivos em que são colocados em jogo", funcionando como uma série de formações imaginárias que designa o que cada um atribui a si e ao outro, ou seja, a imagem do seu lugar e do lugar do outro no discurso.

Também em Pêcheux (1995) buscamos o significado de "bom sujeito" e de formação discursiva, como "o todo complexo com uma dominante", juntamente com Indurski (2000), porque essa autora deixa nítido que a constituição do sentido e do sujeito implica a compreensão de que as noções de homogeneidade e 
heterogeneidade devem ser entendidas como parte da evolução do conceito de formação discursiva, no processo de identificação do sujeito.

Neste trabalho, entendemos uma formação discursiva como homogênea quando o sujeito do discurso se identifica com a formação discursiva diretamente ligada à forma-sujeito que a organiza, ou seja, sem a "mediação" das "posições"; e como heterogênea quando o sujeito "precisa identificar-se com a forma-sujeito pelo viés de uma posição-sujeito inscrita em uma formação discursiva, pois cada posição-sujeito representa diferentes modos de se relacionar com a forma-sujeito" (INDURSKI, 2000, p. 77).

\section{Paráfrase e polissemia}

Como elementos iniciais de análise recorremos aos verbos ungir escolher do recorte (R01) e aos verbos ide e pregai do recorte (R02) retirados dos enunciados das missionárias e desenvolvemos uma análise discursiva, com apoio nas citações diretas e nas paráfrases relacionadas às citações também enunciadas pelas missionárias.

(R01) "Isaías 71 que Ele diz assim: 'eu te ungipara isso, eu te escolhipara isso"' (E1).

(R02) "Ide por todo o mundo, pregai o evangelho a toda criatura" (E1).

No recorte discursivo (R01), o verbete ungirquer dizer: 1. Aplicar óleo ou ungüento a; 2. Esfregar de leve com substância gordurosa; 3. Dar a unção a, com os santos óleos; 4. Aplicar a extrema-unção a; e 5. Investir de autoridade, poder etc. $\mathrm{O}$ mesmo dicionário define o verbete escolher como: 1. Optar (entre duas ou mais coisas ou pessoas), preferir; 2. Eleger, nomear; e 3. Selecionar. O verbo escolher adquire a forma escolhido, que pode ser usada como adjetivo ou como substantivo (XIMENES, 2000). 
Com relação ao recorte (R02), de acordo com a norma-padrão, ide e pregai são verbos de $2^{a}$ pessoa do imperativo afirmativo, cuja pessoa é definida como "aquela a quem se fala". Segundo a gramática de Cunha e Cintra (1985, p. 465), no que diz respeito ao modo verbal, "à atitude da pessoa que fala em relação ao fato que enuncia", a palavra imperativo está ligada, pela origem, ao latim imperare, que significa "comandar".

As seqüências (R01) e (R02) trazem citações bíblicas que recobrem o dito da missionária, visto que $\mathrm{o}$ locutor não apenas repete as citações através das paráfrases que desenvolve; nesses recortes, o locutor faz uso do discurso citado, inclusive indicando a fonte da citação, "Isaías 71", que é um dos membros da hierarquia divina.

Nesse contexto, podemos dizer que, de uma posição de comando, ao falar diretamente com o sujeito/ locutor da esfera material, o locutor da esfera espiritual impõe uma ordem, uma missão, tornando o sujeito/homem Seu representante na terra e autorizando-o a divulgar a Sua palavra.

\section{O Movimento Parafrástico}

\subsection{Paráfrases referentes ao Recorte 01 :}

Quando analisamos os recortes de (P01) até (P10) abaixo, observamos que eles são as paráfrases de (R01) "Isaías 71 que Ele diz assim: 'eu te ungi para isso, eu te escolhi para isso'". Essas seqüencias parafrásticas referemse ao verbo ungir, principalmente na acepção 5 (investir de autoridade, poder), mas também faz referência à acepção 3 (dar a unção a, com os santos óleos); referemse também ao verbo escolher, significando preferência, predileção, nas três acepções supracitadas. As paráfrases enunciadas pelas missionárias criam o efeito de sentido de que elas são "ungidas", "escolhidas" por Deus.

(P01) "Eu tive a certeza de que Deus me queria" (E1) 
(P02) "Era o trabalho que Ele tava mostrando para mim naquela noite" (E1)

(P03) "O trabalho que Ele havia me chamado" (E1)

(P04) "Deus que nos escolhe a fazer uma tarefa específica” (E3)

(P05) "Essa missão que Deus lhe [me]1 deu” (E3)

(P06) "Eu amo estar aqui fazendo a vontade de Deus porque eu tenho esse chamado"(E3)

(P07) "Esse é o trabalho do missionário: fazer a vontade de Deus, independente do lugar, independente do que seja, mas simplesmente obedecer de acordo com aquilo que Ele quer" (E3)

(P08) "O missionário, ele não se forma, ele é chamado por Deus" (E5)

${ }^{1}$ Nesse uso há também uma referência ao locutor.

(P09) "Deu pra falar no coração que eu fui chamada a ser missionária” (E5)

(P10) "Eu tenho assim, um dom, eu não sei se é dom, não sei o que é" (E5)

\subsection{Paráfrases referentes ao Recorte 02 :}

Os recortes discursivos de (P11) até (P19) são as paráfrases correspondentes ao recorte (R02), "Ide por todo o mundo, pregai o evangelho a toda criatura". Com essas paráfrases, o locutor produz o efeito de sentido de que têm a missão de "pregar" a palavra de Deus.

(P11) "Primeiro de tudo foi trabalhar para ajudar pessoas, não é? Sobretudo ajudar as pessoas, proteção espiritual, ter um encontro com Cristo" (E2) 
(P12) "A tarefa do missionário élevar a Palavra de Deus para as pessoas que não conhecem" (E3)

(P13) "E o mais importante é esse, levar a Palavra" (E3)

(P14) "Então quando a gente leva a Palavra de Deus para as pessoas" (E3)

(P15) "O seu desejo é muito grande de você falar com outras pessoas sobre Jesus"(E6)

(P16) "Tem o desejo grande, ardente de você falar de Jesus com outras pessoas"(E6)

(P17) "Somos nós os (inint) missionários que temos que levar essa mensagem a toda criatura, seja aonde for" (E6)

(P18) "E que você chega ali e prega a palavra de Deus"(E6)

(P19) "E você chegou, ali, naquele momento, levando a palavra àquelas pessoas"(E6)

As seqüências discursivas de (R02) repetem a mesma idéia contida em (R01) de ser o sujeito locutor da esfera terrena escolhido por Deus para divulgar a Sua palavra "a toda criatura". Servem como exemplo para essa interpretação os trechos extraídos dos recortes seguintes:

(P11) "Sobretudo ajudaras pessoas, proteção espiritual, ter um encontro com Cristo ”(E2)

(P12) "A tarefa do missionário é levara Palavra de Deus para as pessoas que não conhecem "(E3)

(P13) "E o mais importante é esse, levar a Palavra”(E3)

(P14) 'Então quando a gente leva a Palavra de Deus para as pessoa '(E3) 
(P15) “Falarcom outras pessoas ”(E6)

${ }^{2}$ A palavra de Deus é sempre revelada por algum componente da hierarquia divina, como, por exemplo, o profeta, que é um representante de Deus no Velho Testamento. Na Bíblia (1996), no dicionário bíblico, profeta é definido como o principal título dado por Deus. "De todos os títulos, pelos quais no Velho Testamento se referem àqueles que recebiam os oráculos de Deus para o homem, o principal é profeta. Outros são vidente, homem de Deus (I Sam. 9:7-10), servo do Senhor (Deut. 34:5), mensageiro de Deus (Mat. 3:1)". (Cf referência bibliográfica, p. 154).

${ }^{3}$ Membro da hierarquia divina, no Velho

Testamento. A voz de Deus está sempre sob representação, por isso os recortes acima são citações diretas utilizadas pelo locutor (a missionária), atribuídas ao profeta.
(P16) “Falarde Jesus com outras pessoas ”(E6)

(P17) "Temos que levar essa mensagem "(E6)

(P18) "Você chega ali e prega a palavra"(E6)

(P 19) "Você chegou ali ... levando a palavra "(E6)

\subsection{Posições-sujeito: uma tentativa de controle da polissemia?}

Em (R01), os verbos ungi e escolhi referem-se à condição de predestinação do locutor; em (R02), os verbos ide e pregai confirmam a idéia de que o locutor tem de ser o pregador, o divulgador da palavra de Deus.

Nos recortes acima, o uso do discurso direto e das paráfrases para relatar uma mesma enunciação representa duas estratégias diferentes, porém correlatas. Através desses mecanismos, o sujeito constitui um quadro de elementos da polifonia presentes na enunciação, que se distinguem como modo de representação do sujeito do discurso.

Quanto ao discurso citado ${ }^{2}$ e às paráfrases, há uma aproximação dos enunciados, sendo que o dito do sujeito (discurso citado) se sobrepõe ao dito do locutor (paráfrases). Assim, ao utilizar as paráfrases e também trazer a citação do texto parafraseado para a textualidade, o locutor pretende sobrepor a citação à paráfrase.

A aproximação dos dois discursos não é uma estratégia empregada pelo locutor para ocultar-se na citação enunciada ou mesmo para contestá-la porque não acredita naquilo que é afirmado nela. Ao contrário, o locutor pretende que a verdade das paráfrases empregadas seja idêntica àquela contida no texto parafraseado e citado.

A sobreposição do discurso citado, que é o discurso do profeta, ${ }^{3}$ ao discurso parafrástico, que é o 
discurso do locutor (missionária), é uma necessidade imperativa à qual o locutor se submete, submissão essa derivada da formação discursiva à qual pertence. A imposição para o recobrimento de um efeito de sentido em relação a outros possíveis é uma forma de coerção aceita pelo locutor para que possa permanecer inserido na mesma formação discursiva do sujeito universal e dele receber a unção. Esse mecanismo faz funcionar o discurso religioso.

De acordo com Maingueneau, "cada formação discursiva deve apelar à autoridade pertinente, considerando sua posição, na enunciação" (1993, p. 86). Assim, os enunciados bíblicos ${ }^{4}$ relatados e parafraseados funcionam por leis coercitivas dadas pelo lugar que o sujeito discursivo ocupa na enunciação. Tais coerções regulam as citações e as paráfrases, que são mecanismos discursivos característicos do funcionamento do discurso religioso.

Nessa perspectiva, a paráfrase aparece como uma tentativa de controle da polissemia dada pela língua e pelo interdiscurso. Melhor dizendo, por tal mecanismo discursivo, o modo de representação do sujeito do discurso funciona como uma forma de apagamento da alteridade existente. Tal apagamento é dado pelo recobrimento do dito do citado pelo dito do citando.

Através do processo parafrástico, o locutor é investido de autoridade e poder pelo sujeito universal por ter sido preferido pelo poder divino porque recebeu o chamado de Deus. Assim, o locutor torna-se um sujeito predestinado, que, devido a essa predestinação, foi eleito por Deus e, em razão disso, pode falar em Seu nome, como confirmam as paráfrases de (R01) e de (R02), que se seguem:

(P01) "Eu tive a certeza de que Deus me queria"(R01E1)

(P02) “Era o trabalho que Ele tava mostrando para mim naquela noite"(R01E1)
${ }^{4} \mathrm{O}$ sentido da palavra Bíblia desliza para outras, como Deus, Igreja, Irmão, Disciplina. Por isso, defini-las categoricamente requer uma separação nem sempre encontrada no discurso religioso. Assim, a centralidade da Bíblia no processo de doutrinamento na ética batista é o feito metafórico para "a verdade". 
(P12) "A tarefa do missionário é levar a Palavra de Deus para as pessoas que não conhecem" (R02E3)

(P18) “Você chega ali e prega a palavra”(R02E6)

Devido a esse chamamento, o locutor tem a missão de "falar de Jesus com outras pessoas" (P16) e de "levar essa mensagem"(P17). Enfim, desse lugar, o sujeito tem permissão para divulgar a palavra de Deus e, por isso, está autorizado pelo divino a explicá-la ao seu interlocutor na terra para que ele a entenda exatamente como o sujeito universal Deus a enunciou.

O representante está autorizado pelo poder divino a traduzir o discurso enunciado; porém, a condição primordial, ou melhor, a proibição primeira, é que a tradução não deva romper com o sentido já dado pelo

${ }^{5}$ Reportamo-nos ao conceito de (ilusão) de reversibilidade de Orlandi (1986), sem perder de vista a relação de subjetividade de Benveniste (1988). representado, configurando esse discurso como o discurso do bom sujeito (PÊCHEUX, 1995), que deve harmonizarse, sem resistência, com o discurso da formação discursiva à qual pertence.

\section{CONCLUSÃO COM INTERROGAÇÃO: REPRODUUÇÃO DE DISCURSO, FECHAMENTO DE SENTIDO: É POSSIVEL MANTER INTACTO O SENTIDO?}

Conforme demonstramos acima, o sujeito/locutor da esfera material faz uso das paráfrases como recurso que favorece a reprodução de um discurso na tentativa de fechar o sentido, ou seja, procura apagar a polissemia e, portanto, impossibilitar o conflito, a ruptura, com o intuito de homogeneizá-lo para não polemizar e, assim, manter intacto o sentido único da palavra de Deus.

Como modo de movimento do sujeito e do sentido, o locutor utiliza-se de mecanismos discursivos que trabalham a paráfrase, porque, no discurso religioso, é impossível a interlocução dinâmica ${ }^{5}$ com o sujeito da esfera espiritual, tendo de manter-se no lugar específico do locutor terreno. 
Orlandi (2003) afirma que em todo dizer se mantém algo do dizível, da memória, possibilitando ao locutor trabalhar para manter o sentido já dado pelo sujeito universal, utilizando os processos parafrásticos e, desse modo, caracterizando o discurso religioso. Com tal entendimento, podemos afirmar que a representação do sujeito universal (Deus), através dos dispositivos discursivos da paráfrase e da polissemia e (da ilusão) da reversibilidade, constitui o discurso religioso. 


\section{Referências}

ALMEIDA, João Ferreira de (Tradução). Bíblia: concordância e dicionário. ed. revista e corrigida na grafia simplificada, $86^{9}$ impressão. Rio de Janeiro: Imprensa Biblica Brasileira, 1996.

BENVENISTE, É. Problemas de lingüística geral II. Campinas: Pontes, 1988.

CUNHA, Celso; CINTRA, Lindley. Nova gramática do português contemporâneo. 2. ed., Rio de Janeiro: Nova Fronteira, 1985.

INDURSKI, Freda. A fragmentação do sujeito em Análise do Discurso. In.: INDURSKI, Freda; CAMPOS, M. do Carmo. Discurso, memória e Identidade. Porto Alegre: Sagra Luzzatto, 2000. p. 70-81.

MAINGUENEAU, D. Novas tendências em análise do discurso. 2. ed. Campinas: São Paulo: Pontes, 1993. . Termos-chave da Análise do Discurso. São Paulo: Editora da UFMG, 1998.

ORLANDI, Eni Pulcinelli. Análise de Discurso:princípiose procedimentos. 5. ed., São Paulo: Pontes, 2003.

. A linguagem e seu funcionamento: as formas do discurso. 4. ed., São Paulo: Pontes, 1986.

PECHEUX, M. Semântica e discurso : uma crítica à afirmação do óbvio. Campinas: Unicamp, 1995.

Pontes, 1990.

. O discurso: estrutura ou acontecimento. Campinas: . Delimitações, inversões, deslocamentos. Trad. de José Horta Nunes. In: Caderno de Estudos Lingüísticos. Campinas: Editora da Unicamp, nº 19, p. 7-24, jul/dez 1990. XIMENES, Sérgio. Minidicionário ediouro da língua portuguesa. 2. ed. reformada. São Paulo: Ediouro, 2000. 